\title{
Holistic investigation chain for the experimental determination of fracture mechanical material parameters with special specimens
}

\author{
Deborah Weiß $^{1}\left[\right.$ D $\cdot$ Britta Schramm ${ }^{1} \cdot$ Gunter Kullmer $^{1}$
}

Received: 15 October 2021 / Accepted: 30 November 2021 / Published online: 23 December 2021

(c) The Author(s) 2021

\begin{abstract}
In addition to the classical strength calculation, it is important to design components with regard to fracture mechanics because defects and cracks in a component can drastically influence its strength or fatigue behavior. Cracks can propagate due to operational loads and consequently lead to component failure. The fracture mechanical analysis provides information on stable or unstable crack growth as well as about the direction and the growth rate of a crack. For this purpose, sufficient information has to be available about the crack location, the crack length, the component geometry, the component loading and the fracture mechanical material parameters. The fracture mechanical properties are determined experimentally with standardized specimens as defined by the guidelines of the American Society for Testing and Materials. In practice, however, especially in the context with damage cases or formed material fracture mechanical parameters directly for a component are of interest. However, standard specimens often cannot be extracted at all due to the complexity of the component geometry. Therefore, the development of special specimens is required whereby certain arrangements have to be made in advance. These arrangements are presented in the present paper in order to contribute to a holistic investigation chain for the experimental determination of fracture mechanical material parameters with special specimens.
\end{abstract}

Keywords Fracture mechanics $\cdot$ Experimental procedure $\cdot$ Special specimen $\cdot$ Characterization $\cdot$ Metal sheet $\cdot$ Simulation

\section{Introduction}

Many components and structures are often solely designed according to classical strength calculation based on stresses, deformations or stability aspects. However, defects and cracks located in a component can fundamentally change its strength or fatigue behavior. During operation, cracks can propagate, leading to sudden failure of the component and thus catastrophic damage. In order to predict stable as well as unstable crack growth, the crack propagation direction and the crack growth rate, it is important to carry out a fracture mechanical analysis in addition to the classical strength calculation. Therefore, knowledge about the crack, the component geometry, the loading situation and the fracture mechanical material parameters is required [1]. In general, these material parameters (e.g. the threshold against fatigue crack growth $\Delta K_{\mathrm{I}, \mathrm{th}}$ or the entire crack growth rate

Deborah Weiß

weiss@fam.upb.de

1 Applied Mechanics (FAM), Paderborn University, Pohlweg 47-49, 33098 Paderborn, Germany curve) are determined experimentally using standardized specimens according to the American Society for Testing and Materials (ASTM) [2]. However, a major challenge in practice is to characterize the material behavior especially in complex components locally. Often it is not possible to take standard specimens directly from the component. Therefore, miniaturized compact tension (CT)-specimens have already been developed and utilized for smaller components [3, 4]. However, sometimes the development of special specimens is required due to different challenges (e.g. component geometry or thickness) in order to investigate the fracture mechanical properties of the component's material.

Within the scope of this paper, the investigation chain for the experimental determination of fracture mechanical material parameters with special specimens is presented holistically. In order to determine the crack length $a$ and the cyclic stress intensity factor $\Delta K_{\mathrm{I}}$ of a novel special specimen, preliminary numerical simulations have to be carried out to get the calibration function as well as the geometry factor function. Hence, in addition to the discussion of different challenges and the illustration of various special specimens, the general experimental procedure, the measuring method 
for determining the crack length during the experiments as well as the subsequent evaluation of the experimental results are discussed in the paper.

\section{Discussion of different challenges and various special specimens}

The introduction of this paper has already highlighted the importance of dealing with fracture mechanics in addition to classical strength calculation. In the past, there have been numerous damage cases where small defects or cracks were the trigger for the failure of the structure. Examples include fractured pistons in trucks [1], see Fig. 1, a broken hydraulic press [5-7] as well as the disastrous ICE accident in Eschede in 1998 due to a broken wheel tire $[8,9]$ and further damages in train structures $[10,11]$.
For the prevention of these damage cases, the local fracture mechanical material properties must be known in order to be able to describe and predict the crack growth in the components. Therefore, it is necessary that the specimens are taken directly from the affected structure so that influences due to the manufacturing process or due to heat treatments can also be taken into account. In most of the occasions, the standardized CT-specimen cannot be extracted for complex or small structures to analyze the fatigue crack growth behavior because the CT-specimen according to the ASTM E 647 has defined dimensional ratios and suggests a minimal dimension of $\mathrm{w}=25 \mathrm{~mm}$, see Fig. 2.

To include all influencing factors of the component under investigation, special specimens are required. Their preparation poses various challenges. In this section, these different challenges in determining fracture mechanical parameters are discussed among other things by means of an engine

Fig. 1 Fractured truck piston

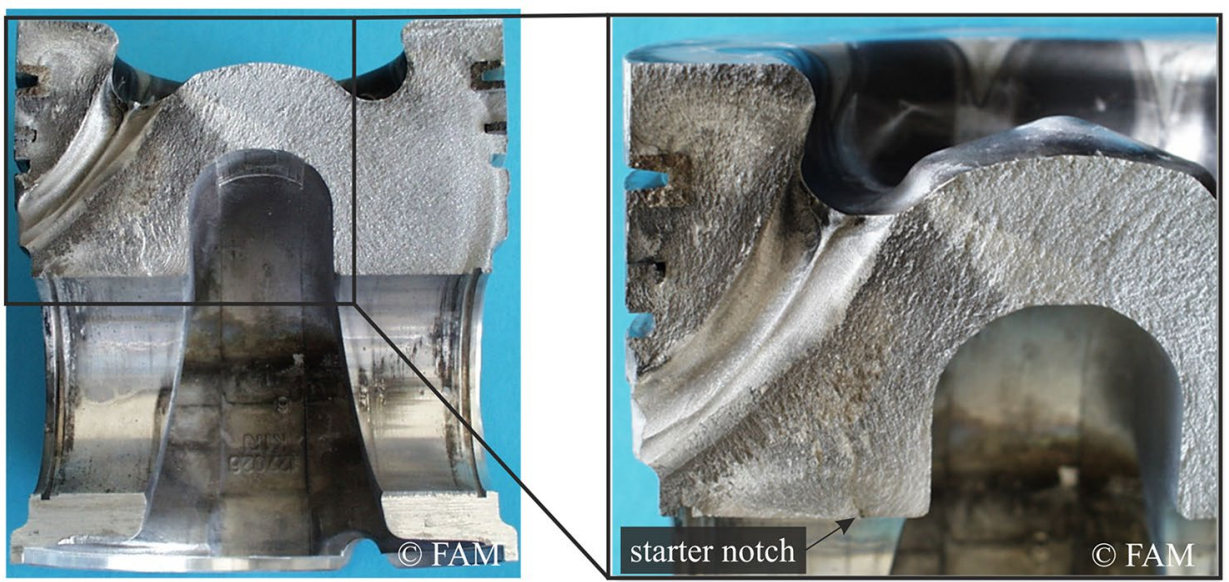

Fig. 2 Dimensional ratios of the CT-specimen according to the ASTM E 647 [2]
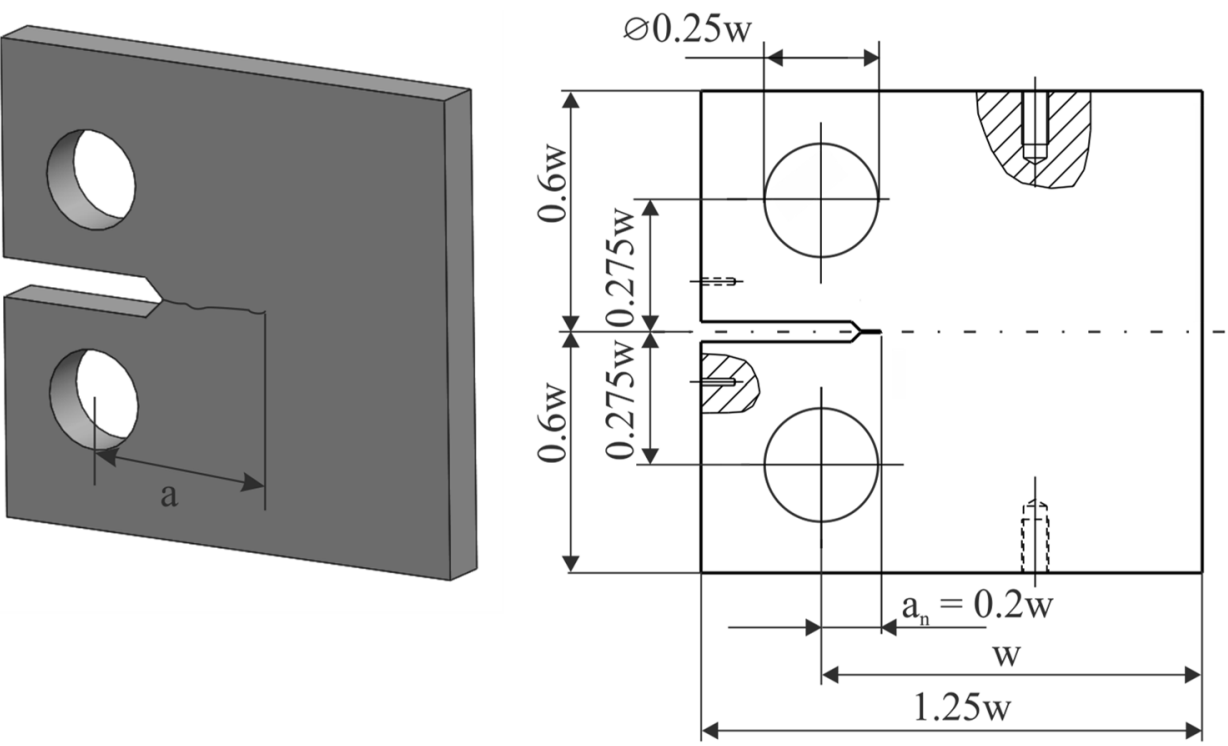
piston of a truck. Furthermore, different special specimens are illustrated. In general, restrictions exist on sampling in terms of geometry, material and production $[1,12]$. On the one hand, for the cast piston it is not possible to produce specimens with the same casting conditions as the original component. On the other hand, it is impossible to utilize the standardized CT-specimen according to Fig. 2 because of the component's geometry, see Fig. 1. Therefore, a special specimen, called C-specimen because of its c-shape, was developed to characterize the piston fracture mechanically, see Fig. 3a.

Another example that requires the specimen to be adjusted to the component is a slat track in an aircraft wing. Slat tracks are safety-critical components because they are necessary for the movement and guidance of the slats to increase lift, especially during takeoff and landing. Therefore, they are made of very high-strength titanium or steel alloys with very high safety factors. For the determination of fracture mechanical parameters of the material, a modified CT-specimen was used, see Fig. 3b. The graphic presents the dimensions of the specimen, which differ from the standard specimen's dimensional ratios as specified in the ASTM standard, since the drill holes located in the slat track had to be taken into account for the creation of the specimen geometry, see Fig. 2 [1, 12].

The main focus of the paper is on the fracture mechanical evaluation of metal sheets used in a clinching process because clinching is a very common joining method in industrial manufacturing processes due to various advantages. On the one hand, clinching can combine diverse as well as coated materials and does not need any consumables [13]. That is why this joining method is frequently applied in the automotive sector to design cars according to multimaterial design. Using multi-materials and eliminating

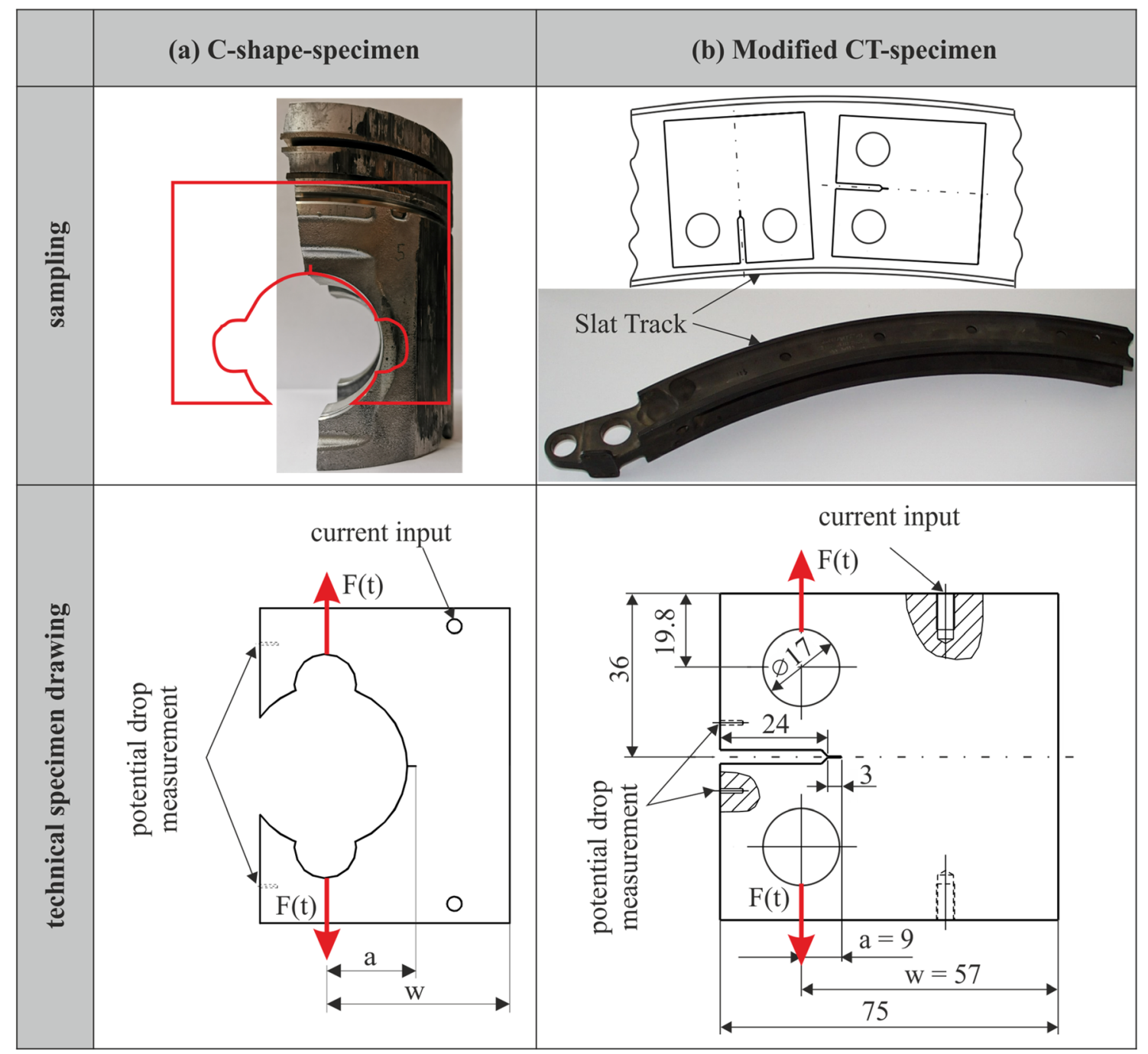

Fig. 3 Comparison of the sampling and the technical specimen drawing on the basis of the a C-specimen; $\mathbf{b}$ modified CT-specimen 
consumables enables the weight reduction of cars, which at the same time lowers hazardous $\mathrm{CO}_{2}$ emissions [14]. In this way, car manufacturers are able to comply with the $\mathrm{CO}_{2}$ consumption values required by the European Commission [15]. On the other hand, clinching does not require pre-drilled holes and can be performed in only one step, making it a simple and cost-effective method [13]. The primary field of application is for maximum total sheet thicknesses up to $4 \mathrm{~mm}$ [16].

For the fracture mechanical evaluation of the metal sheets used in the clinching process, the significant challenges for designing special specimens are (1) the thin sheet thickness of merely $1.5 \mathrm{~mm}$, (2) the requirement to locally characterize the joint in a fracture mechanical way and (3) the consideration of certain influencing factors (like plastic pre-deformation). In order to characterize the entire clinched structure, various special specimens extracted directly from the undeformed material, the predeformed metal sheet as well as of the clinched structure are required. First, however, it is essential to find out how the base material behaves from a fracture mechanical point of view. As already mentioned in the introduction, the metal sheets of the base material have a thickness of only $1.5 \mathrm{~mm}$, which complicates the crack length measurement during the experiment. For standardized specimens, the current is introduced via solder pins, which are attached to the side face. Due to the low sheet thickness, these solder pins have to be transferred to the front face resulting in an extension of the specimen thighs [17, 18]. The final extended Mini-CT-specimen is illustrated in Fig. 4a and is compared to the miniaturized CT-specimen according to the dimensional ratios illustrated in Fig. 2 but with a $w=20 \mathrm{~mm}$. The Mini-CT-specimen was developed for very small components where the minimum dimensions proposed by ASTM E 647 standard could not be respected, but whose functionality has been validated by various researchers $[3,4]$. The general experimental procedure is explained on the basis of the extended Mini-CT-specimen in the following sections.

When designing special specimens, it is additionally important to have the highest maximum principal stresses at the starter notch to ensure that the crack initiates in this region in the subsequent test, see Fig. 4b. Furthermore, some preliminary numerical simulations have to be carried out before the special specimens can be tested experimentally. The presentation of the holistic experimental process for the determination of fracture mechanical parameters is described in the following exemplary on the basis of the extended Mini-CT-specimen.

\section{Experimental determination of fracture mechanical material parameters}

For experimental investigations of fatigue crack growth, the test setup shown schematically in Fig. 5 can be used for electrically conductive materials. For example, the aforementioned C-specimen is made of a cast aluminum alloy, the modified CT-specimen consists of a high-strength steel alloy and the extended Mini-CT-specimen is made of HCT590X, which is part of the TRR285. The central unit of the test setup consists of an electro-mechanical tensile testing machine with corresponding electronics and a personal computer for data acquisition and control of the test. Communication is established between the PC and the electronics of the testing machine via a General Purpose Interface Bus (GPIB). The measuring device is used for crack length (a)

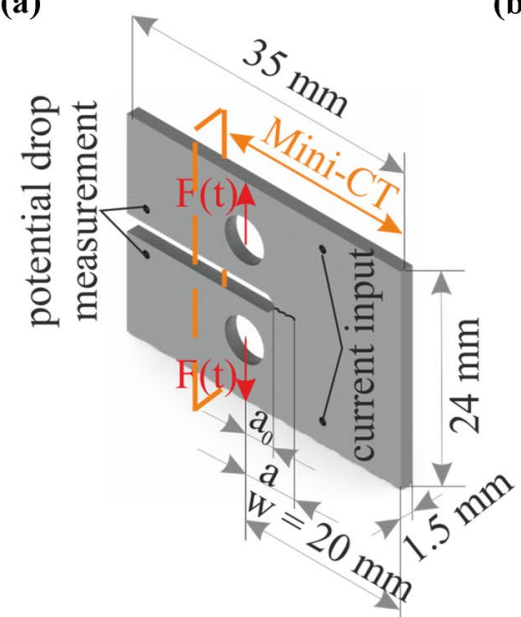

(b)

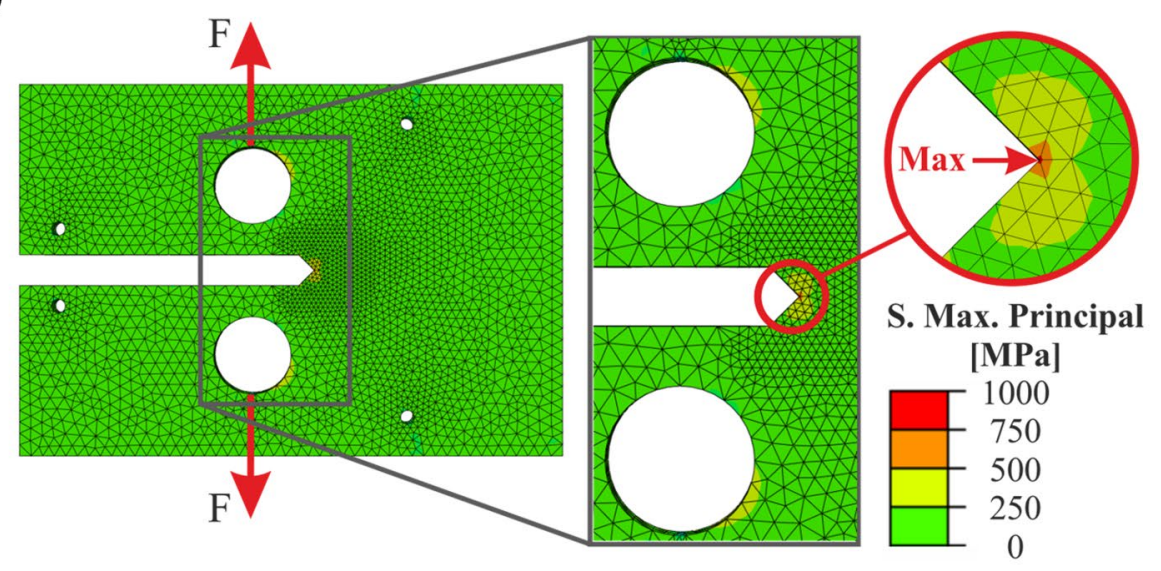

Fig. 4 a Extended Mini-CT-specimen in comparison to the dimensions of the Mini-CT-specimen (orange color); b stress analysis of the loaded extended Mini-CT-specimen (color figure online) 
Fig. 5 Experimental test setup

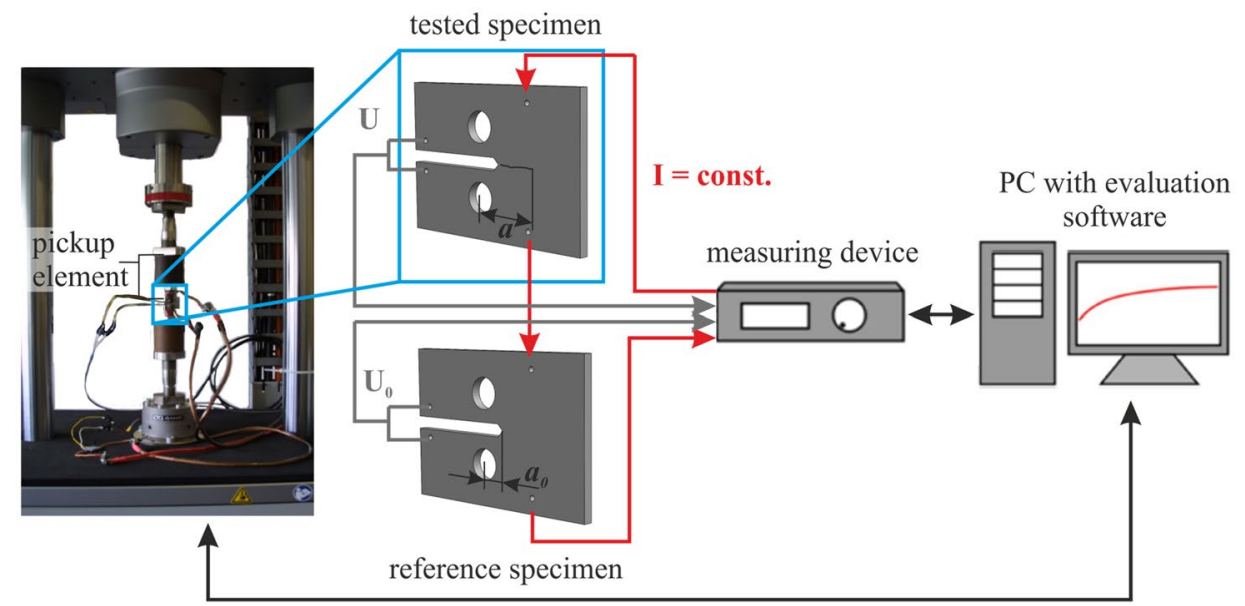

measurement according to the direct current potential drop method [1].

\subsection{Direct current potential drop method}

The determination of the crack growth rate curve requires a continuous crack length measurement during the test. In addition to optical methods, which require an appropriate camera equipment, the crack length $a$ can also be measured by the current potential drop method if the material is electrically conductive. If this is the case, a current is fed into the specimen and the potential difference is measured at specific points. Since the Ohmic resistance increases as a result of the crack growth due to the reduction of the crosssection, the associated crack length can be determined from the change in potential by means of a calibration curve [1]. A distinction is made between the direct current and the alternating current potential drop method, with the direct current potential drop method being the more common and having found application in many different studies [1, 3, 17-20].

In the direct current potential drop method, a constant direct current $I$ is applied to the top of the tested specimen, generating a two-dimensional electric field with a steady state across the specimen thickness. The current level is selected between 5 and $50 \mathrm{~A}$, according to the specimen size and material. Meanwhile, the potential difference is measured above and below the notch. This ensures a current flow around the notch or crack. Then, the current is passed from the specimen to the reference specimen and back to the current source. The measuring device processes the potential difference $U$. Afterwards a personal computer evaluates the signal [1]. Since the current input can lead to a heating of the specimen, a reference specimen is required to correct the measured potential difference [20]. Furthermore, the pickup element is equipped with an insulating element to avoid fault currents [1].
The corresponding crack length $a$ can be derived from the measured potential difference by means of a calibration curve. The ASTM E 647 standard offers corresponding functions for some standardized specimen types [2]. If, as in this paper, a special specimen type is to be used, the calibration function has to be determined by experimental or numerical methods. For the experimental determination of the calibration curve, rest marks are generated on the fracture surface of the specimen with the help of overloads or block loads [20]. After testing, the rest marks on the fracture surface are measured with a microscope to establish an accurate correlation between the average crack length and the potential difference applied at the time of the overload or block load [1].

The numerical determination of the calibration curve can be carried out by means of finite element programs like ABAQUS $^{\mathrm{TM}}$ or LS-DyNA. According to the experimental test setup, an electric current is introduced into the specimen at the drill hole above the notch where the crack starts to grow and is removed from the specimen below the notch, see Fig. 4a. Then, a crack is successively inserted into the specimen at defined distances of, for example, $1 \mathrm{~mm}$. The distances depend on the specimen size and it has to be ensured that there are sufficient support points available to map the calibration curve. The potential difference $U$ is calculated at defined nodes for each crack length. By plotting the $\mathrm{a} / \mathrm{w}$ ratio over $\mathrm{U} / \mathrm{U}_{0}$ the calibration curve is obtained. A compensating curve is laid through the plotted points resulting in the calibration function, e.g. a 4th degree polynomial. Figure $6 a$ shows the fracture surface of the modified CT-specimen including rest marks as well as a comparison between the experimentally and numerically determined calibration curves. The comparison indicates that there are deviations for this specimen, especially in the middle area of the calibration curve. These can be attributed to the fact that the crack fronts of the rest marks are not parallel, which can lead to measurement inaccuracies. Another comparison of an experimentally and a numerically determined calibration 


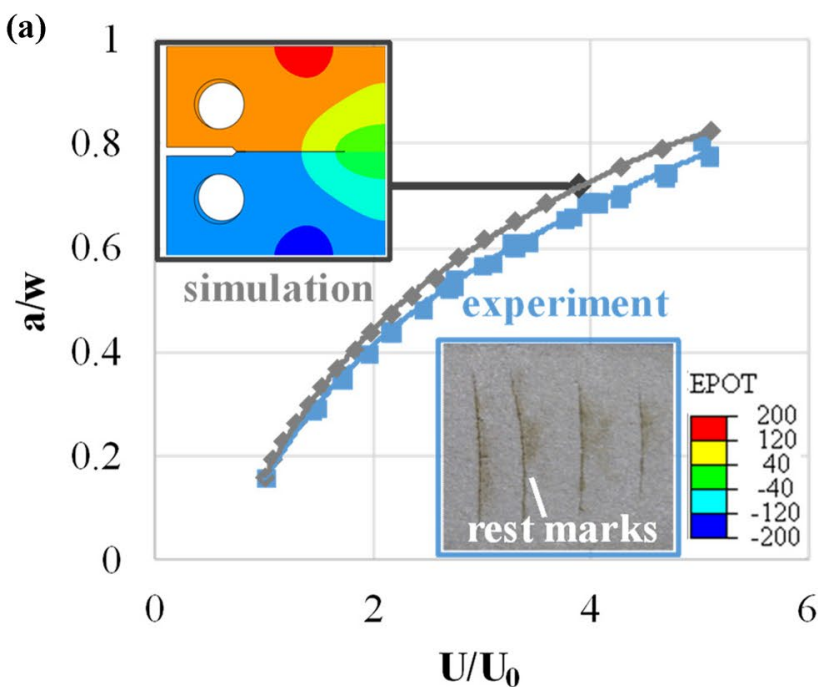

Fig. 6 a Comparison of the experimental and numerical determination of the calibration curve based on the modified CT-specimen; $\mathbf{b}$ comparison of the numerically determined calibration function of

curve based on the Mini-CT-specimen is illustrated in [21]. The result of this comparison is that both methods lead to the same calibration curve. Due to plastification partial crack closure can influence the crack length during the experiment. Therefore, the validation of the calibration function is achieved by measuring the crack lengths under a microscope after the tests and by comparing them with the numerical determination [1]. The numerically determined calibration curve of the extended Mini-CT-specimen as well as the experimentally measured crack lengths, which are visualized with red dots, are illustrated in Fig. 6b. Because the measured crack lengths lie on the numerically determined calibration curve, the procedure for the numerical simulation of the calibration function can be validated, which also confirms the results of Riemer [21]. Furthermore, the experimentally determined calibration curves of the $\mathrm{C}$-specimen and the modified CT-specimen are visualized and the differences of the various calibration curves are illustrated.

The numerically determined calibration function is stored in the interactive program system ${ }^{\mathrm{FAM}}$ Control developed by the Institute of Applied Mechanics (Paderborn University), which is used for measurement data acquisition and control of the fatigue crack growth rate tests [22].

\subsection{Experimental execution}

For the fracture mechanical characterization of the crack growth behavior in components and structures, the determination of the crack growth rate curve $d a / d N-\Delta K$ is necessary. In the following, the experimental execution for estimating this curve is described. (b)

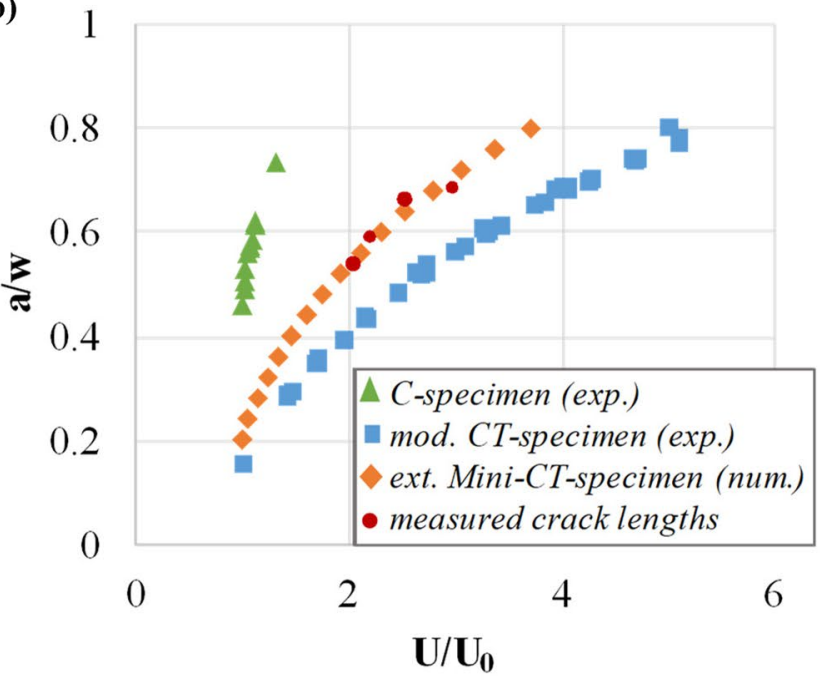

different special specimens and measured crack lengths (red dots) for the extended Mini-CT-specimen (color figure online)

In order to record the entire range of a crack propagation curve, at least two test types with a minimum of three specimens are necessary according to ASTM E 647. Both tests are carried out under a periodic sinusoidal loading with a chosen $R$-ratio of e.g. 0.1 . The $R$-ratio indicates the ratio of lower to upper stress. In the first test, called up-test, the maximum and minimum forces are kept constant, see Fig. 7a. Since at constant force, the stress intensity increases with increasing crack length, the middle and upper regions of the crack growth rate curve are obtained, see Fig. 9.

In a second test, called down-test, shown in Fig. 7b, the middle and lower regions of the crack growth rate curve are examined. During these tests, the cyclic stress intensity factor $\Delta K$ is the test controlling parameter and can be described for mode I loading by the following formula:

$\Delta K_{I}=\Delta \sigma \cdot \sqrt{\pi \cdot a} \cdot Y_{I}$

The cyclic stress intensity factor defines the intensity of the singular stress field and can simultaneously describe the amount of displacements in the vicinity of the crack. The cyclic stress intensity factor is dependent, among various other factors, on crack length, crack depth and crack location as well as on external loads of the structure. All these influences are included in the geometry factor function $Y$ [23]. By converting Eq. (1) to $Y$, the geometry factor can be calculated as follows:

$Y(a)=\Delta K_{I} \cdot \frac{w t}{\Delta F \sqrt{\pi a}}$ 
(a)

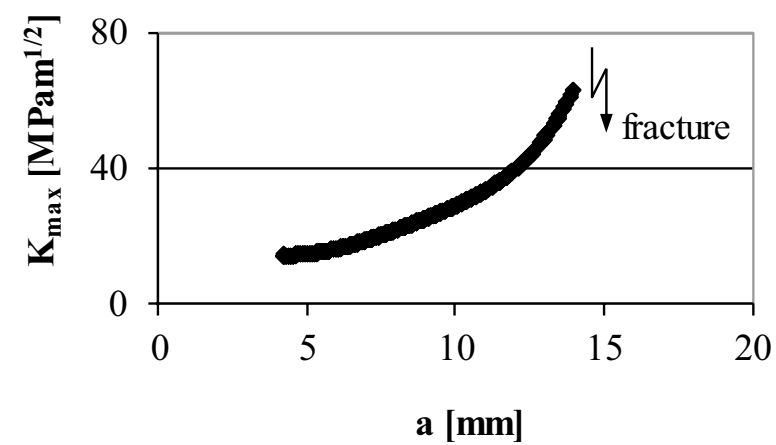

(b)

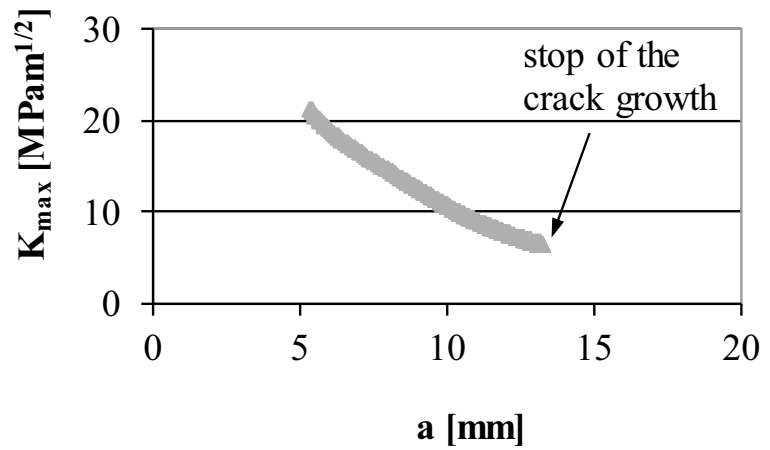

Fig. 7 Tests with $\mathbf{a} \mathrm{F}_{\max }=$ const. (up-test) and $\mathbf{b}$ with exponentially decreasing $\mathrm{K}_{\max }$ (down-test)

In order to determine the geometry factor function $Y$ as a function of the crack length $a$, the cyclic stress intensity factor $\Delta K_{I}$ is required, as shown in Eq. (2). For special specimens with new crack geometries and arbitrary loading conditions, cyclic stress intensity factors can only be determined by numerical methods. Common methods to solve boundary value problems numerically in the field of solid mechanics are the finite-element method (FEM) [24, 25] and the boundary-element method (BEM) [26, 27]. Taking into account the FEM, the whole specimen is discretized into a finite number of adequately tiny elements. There, the displacements can be approximated among other things by standardized shape functions which result in a linear system of equations [23]. Following its numerical solution, the displacement field values are received in the nodes, whereas the stress field values are obtained in the integration points [28]. From these displacements and stresses calculated in the entire specimen, the cyclic stress intensity factors can be extrapolated with the help of the numerical solution in the vicinity of the crack-tip [23].

The cyclic stress intensity factors along the crack front are calculated for each specimen type using automatic crack growth simulation programs like ADAPCRACK3D [29, 30] or FRANC3D [31]. For this purpose, a numerical model with boundary conditions and loads according to the experiments is read into the crack growth simulation program. The stress analysis of Fig. $4 \mathrm{~b}$ can serve as an exemplary numerical input model for the crack growth simulation. Then a crack is initiated to run a crack growth simulation. By calculating the cyclic stress intensity factors $\Delta K$ in relation to the crack length $a$, the geometry factor function can be determined by means of Eq. (2). In Fig. 8a the extended crack fronts, at which the cyclic stress intensity factors are determined, are visualized with help of red lines. A comparison of the different geometry factor functions of the presented special specimens are illustrated in Fig. 8b. From the diagram, there is a clear indication that the extended Mini-CT-specimen and (a)

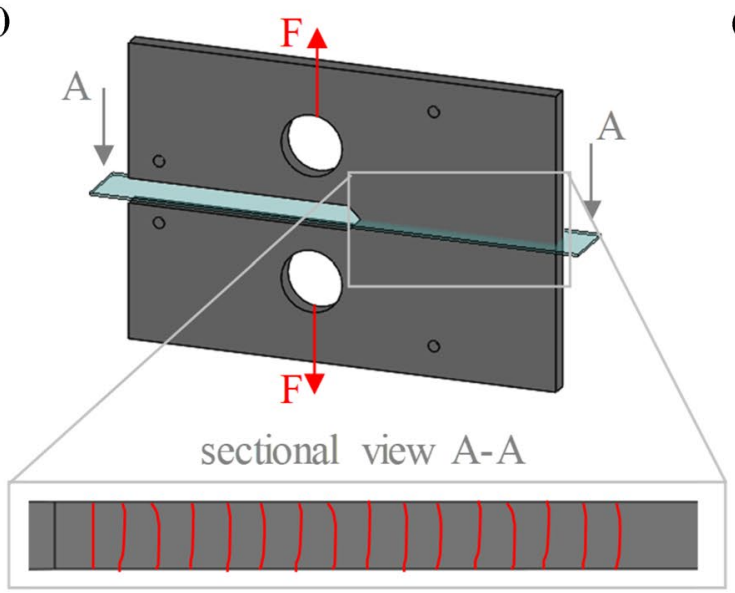

(b)

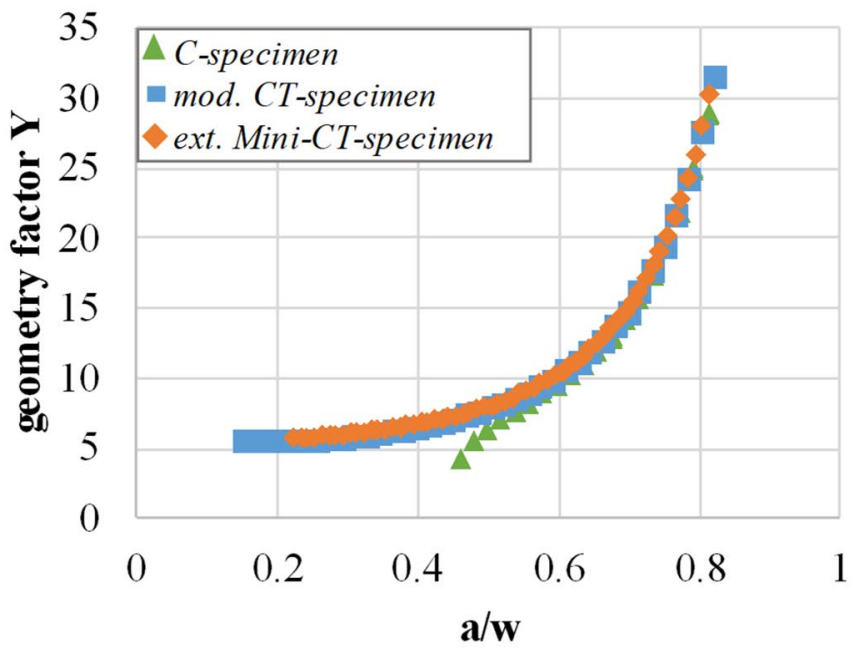

Fig. 8 a Extended crack fronts (red lines); b comparison of the different geometry factor functions of the presented special specimens 
the modified CT-specimen have the same geometry factor function due to the high similarity of the specimen geometry. Only the C-specimen deviates from the others in the initial region of the curve.

By inserting the numerically determined geometry factor function into the test program ${ }^{\mathrm{FAM}} \mathrm{Control}$, stress intensity controlled tests like the down-test can be carried out. First, a pre-crack is initiated into the specimen under cyclic loading with a constant cyclic stress intensity factor $\Delta K$. The initial cyclic stress intensity factor $\Delta K_{0}$ is selected in such a way that the crack starts growing at medium crack growth rate. To eliminate any mechanical effects of the notch, the length of the pre-crack shall be longer than $10 \%$ of the specimen thickness or the notch height $h$, whichever is greater, but at least $1.0 \mathrm{~mm}$ measured from the machined notch [2]. After initiating a pre-crack, the ASTM E 647 standard recommends an exponential decrease in stress intensity starting from an initial value $\Delta K_{0}$ with a decrease rate $C$ until the crack stops growing, according to Eq. (3). In the equation, $a$ is the measured crack length and $a_{0}$ is the initial crack length at the beginning of the test.

$\Delta K=\Delta K_{0} \cdot e^{C \cdot\left(a-a_{0}\right)}$

Following the ASTM E 647 the decrease rate $C$ has to confirm to the relation:

$C=\frac{1}{K_{I}} \cdot \frac{d K_{I}}{d a}>-0.08 \mathrm{~mm}^{-1}$

Due to adapted geometries and the associated smaller ligament areas, it is not always possible to maintain such a slow decrease rate, especially for special specimens. However, studies by Sheldon et al. [32] or Clark et al. [33] have shown that much faster decrease rates of, for example, $\mathrm{C}=-0.8 \mathrm{~mm}^{-1}$ with an exponential decrease lead to valid thresholds. Another study of [34] illustrates that the achieved threshold for $42 \mathrm{CrNiMo6}$ is with $\Delta K_{\mathrm{th}}=8.77$ $\mathrm{MPam}^{1 / 2}$ lower at a faster decrease rate of $\mathrm{C}=-0.15 \mathrm{~mm}^{-1}$ compared to a threshold of $\Delta K_{\mathrm{th}}=9.95 \mathrm{MPam}^{1 / 2}$ at a slower decrease rate of $\mathrm{C}=-0.08 \mathrm{~mm}^{-1}$, resulting in more conservative thresholds at a decrease rate of $\mathrm{C}=-0.15 \mathrm{~mm}^{-1}$ and thus safer fracture mechanical design. Furthermore, the standard deviation of the threshold at a decrease rate of $\mathrm{C}=-0.15 \mathrm{~mm}^{-1}$ is only half of the standard deviation at a decrease rate of $\mathrm{C}=-0.08 \mathrm{~mm}^{-1}$. These investigations emphasize the opportunity to use even faster decrease rates like $\mathrm{C}=-0.15 \mathrm{~mm}^{-1}$ than suggested in the ASTM E 647 .

In addition, when selecting the initial values of the upand the down-test, it is always important to ensure an overlapping zone between both test types. During the two tests, the applied loads, the load cycles and the potential drop are recorded continuously. Based on this information, the crack growth rate curves are determined.

\subsection{Experimental evaluation}

The aim of the aforementioned two test types is to determine the crack growth rate curve $d a / d N-\Delta K$. According to ASTM E 647, the crack growth rate $d a / d N$ can be evaluated using either the secant method or the incremental polynomial method. The secant method determines the slope of the connection of two successive data points in the $a-N$ curve. The incremental polynomial approximation attempts to determine the crack growth rate $d a / d N$ by fitting a parabola to the test data. For the experimental evaluation of the extended Mini-CT-specimen, the secant method was used to determine the crack growth rate. The cyclic stress intensity factors $\Delta K_{I}$ associated with the crack growth rates have to be calculated from the crack length and the corresponding load range with the help of the numerically determined geometry factor function $Y$. The resulting crack growth rate curves of the different special specimens with typical double-logarithmic axes are illustrated in Fig. 9.

In the diagram, the threshold against fatigue crack growth $\Delta K_{\mathrm{th}}$ and the cyclic fracture toughness $\Delta K_{\mathrm{C}}$ are added. $\Delta K_{\mathrm{th}}$ is the value where the crack crack growth rate $d a / d N$ asymptotically converges to zero. The threshold is the most important fracture mechanical parameter because it indicates the value of cyclic stress intensity from which a crack is able to grow. For long cracks, below the threshold no crack growth is possible. The other fracture mechanical parameter illustrated in the diagram is the cyclic fracture toughness $\Delta K_{\mathrm{C}}$. By dividing $\Delta K_{\mathrm{C}}$ by $(1-R)$, the fracture toughness $K_{\mathrm{C}}$ is obtained. Above this value, unstable crack growth occurs and the component fails [35].

To assess whether the performed fatigue crack growth test is valid, the fracture surfaces after the tests are observed. In Fig. 9, in addition to the resulting crack growth rate curve, two typical crack surfaces of an up- and a down-test can be seen. The fatigue crack growth begins at the starter notch and can be identified by the smooth surface. During a fatigue fracture the crack should grow perpendicular to the normal stress with small deformations even with ductile materials. Care should be taken to ensure that the fatigue crack is symmetrical across the width of the specimen because a one-sided running of the crack indicates that the force is not applied perpendicularly to the center of the specimen thickness. The specimen could have slipped in the pickup element, for example. After the fatigue crack growth, the residual forced fracture is characterized by a very rough surface. Furthermore, shear lips can be observed on the fracture surface. Shear lips, however, indicate large deformations within a residual forced fracture. Especially with thin specimens, made of ductile materials, fracture can lead to very distinctive shear lips. This is because the plastic zone and with this plastifications are even more pronounced on 


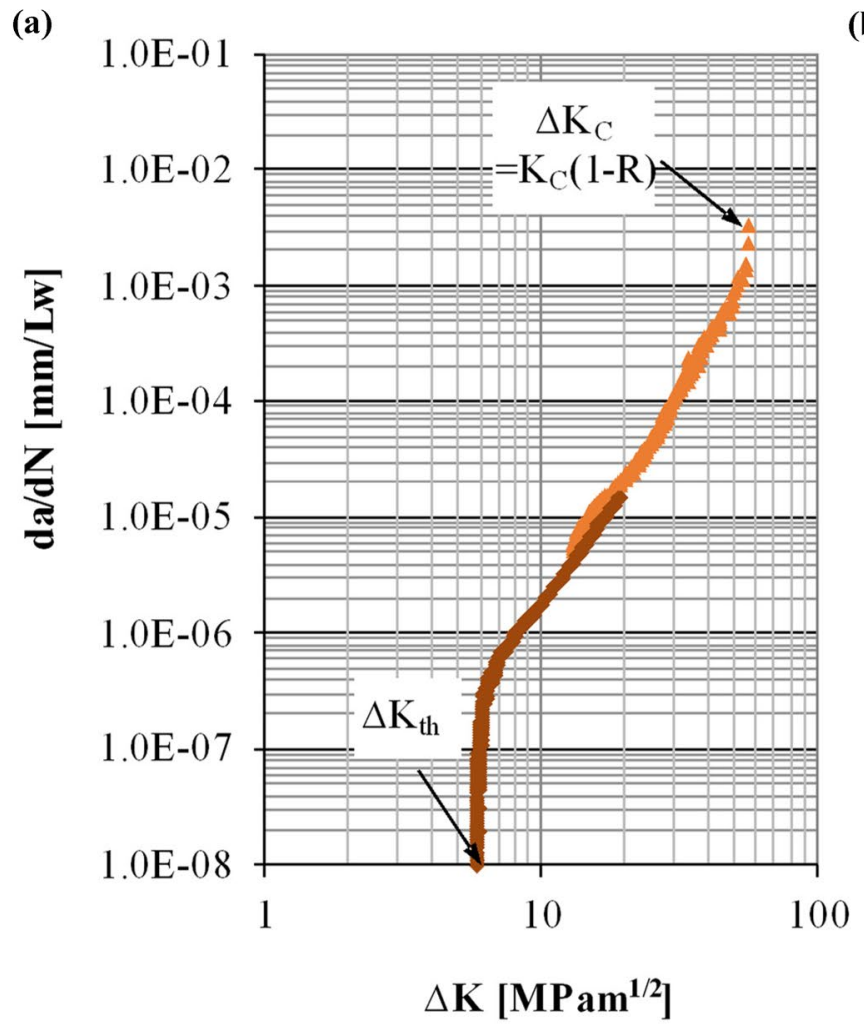

(b)

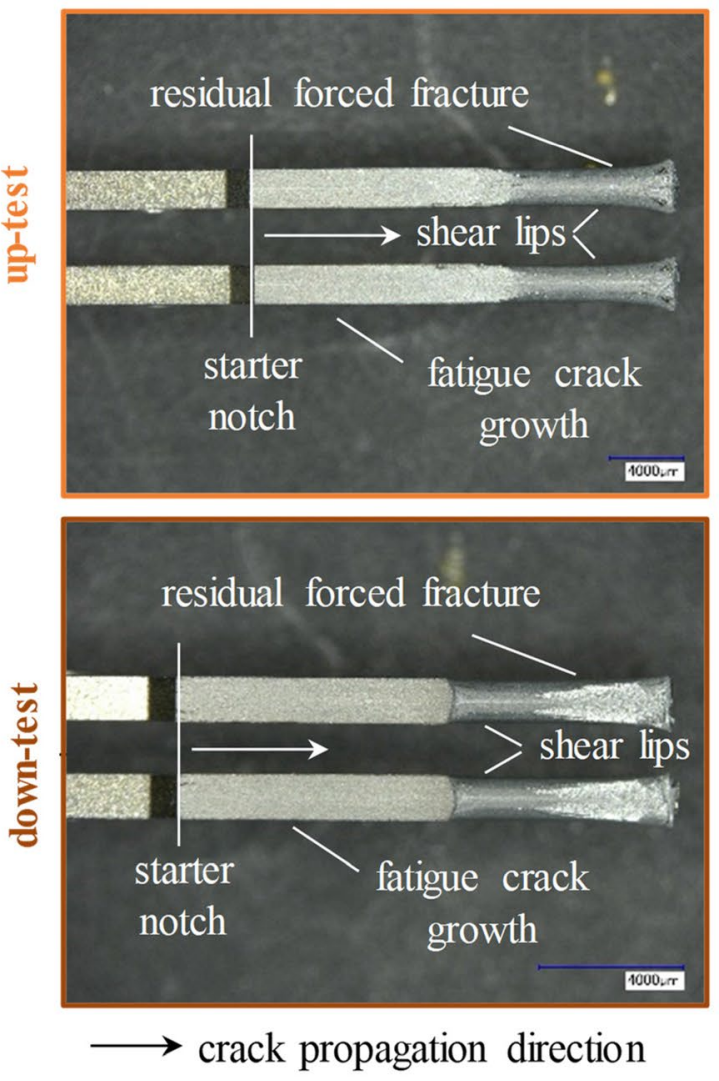

Fig. 9 a Experimentally determined crack growth rate curve of the extended Mini-CT-specimen and $\mathbf{b}$ different fracture surfaces

the surface of the specimen than inside [1]. Furthermore, it must be checked at plate-like components that the specimen is not bulging. The crack surfaces of Fig. 9 clearly show both the fatigue crack growth and the residual forced fracture, which is why these tests can be classified as valid.

\section{Conclusion}

In this paper the holistic investigation chain for the experimental determination of fracture mechanical material parameters with special specimens is presented. It can be stated that due to the various challenges mentioned, it is not always possible to use standard specimens for the determination of fracture mechanical material parameters. In this case, new special specimens have to be developed. The specifics for determining the parameters for special specimens have been addressed in this paper. For these novel special specimens, various arrangements are prepared in advance, such as a general stress simulation of the new geometry to determine the maximum principal stress, the determination of the calibration function for the crack length measurement method during the test and the calculation of the geometry factor function to determine the threshold with the down-tests. Finally, the evaluation of the test results is presented and it is shown on the basis of the resulting fracture surfaces that fatigue crack growth tests can be carried out correctly with special specimen, too. Following the presented holistic investigation chain, special specimens can be developed and used for the experimental determination of fracture mechanical material parameters of components with complex geometries.

Funding Open Access funding enabled and organized by Projekt DEAL. This project was funded by the Deutsche Forschungsgemeinschaft (DFG, German Research Foundation)-TRR 285-Project-ID 418701707 .

Open Access This article is licensed under a Creative Commons Attribution 4.0 International License, which permits use, sharing, adaptation, distribution and reproduction in any medium or format, as long as you give appropriate credit to the original author(s) and the source, provide a link to the Creative Commons licence, and indicate if changes were made. The images or other third party material in this article are included in the article's Creative Commons licence, unless indicated otherwise in a credit line to the material. If material is not included in the article's Creative Commons licence and your intended use is not permitted by statutory regulation or exceeds the permitted use, you will need to obtain permission directly from the copyright holder. To view a copy of this licence, visit http://creativecommons.org/licenses/by/4.0/. 


\section{References}

1. Richard HA, Sander M (2016) Fatigue crack growth: detectassess-avoid. Solid mechanics and its applications. Springer International Publishing, Cham

2. ASTM E647-15e1 (2015) Standard Test Method for Measurement of Fatigue Crack Growth Rates. ASTM International, West Conshohocken, PA. https://doi.org/10.1520/E0647-15E01

3. Riemer A, Leuders S, Thöne M, Richard HA, Tröster T, Niendorf $\mathrm{T}$ (2014) On the fatigue crack growth behavior in 316L stainless steel manufactured by selective laser melting. Eng Fract Mech 120:15-25. https://doi.org/10.1016/j.engfracmech.2014.03.008

4. Schramm B (2014) Risswachstum in funktional gradierten Materialien und Strukturen. Dissertation, Paderborn University

5. Kullmer G, Sander M, Richard HA (2005) Schadensanalyse von Verschlusskörpern einer Innenhochdruckumformmaschine. DVMBericht 237 Technische Sicherheit, Zuverlässigkeit und Lebensdauer, pp 55-64

6. Richard HA, Sander M, Fulland M, Kullmer G (2008) Development of fatigue crack growth in real structures. Eng Fract Mech 75:331-340. https://doi.org/10.1016/j.engfracmech.2007.01.017

7. Fulland M, Sander M, Kullmer G, Richard HA (2008) Analysis of fatigue crack propagation in the frame of a hydraulic press. Eng Fract Mech 75:892-900. https://doi.org/10.1016/j.engfracmech. 2007.01.006

8. Richard HA, Fulland M, Sander M, Kullmer G (2005) Fracture in a rubber-sprung railway wheel. Eng Fail Anal 12:986-999. https:// doi.org/10.1016/j.engfailanal.2004.12.016

9. Esslinger V, Kieselbach R, Koller R, Weisse B (2004) The railway accident of Eschede-technical background. Eng Fail Anal 11:515-535. https://doi.org/10.1016/j.engfailanal.2003.11.001

10. Zerbst U, Mädler K, Hintze H (2005) Fracture mechanics in railway applications-an overview. Eng Fract Mech 72:163-194. https://doi.org/10.1016/j.engfracmech.2003.11.010

11. Madia M, Beretta S, Zerbst U (2008) An investigation on the influence of rotary bending and press fitting on stress intensity factors and fatigue crack growth in railway axles. Eng Fract Mech 75:1906-1920. https://doi.org/10.1016/j.engfracmech.2007.08.015

12. Sander M, Richard HA (2004) Ermittlung bruchmechanischer Kennwerte im Bereich der Verkehrstechnik. DVM-Bericht 236 Fortschritte der Bruch- und Schädigungsmechanik, pp 131-140

13. Dietrich J (2018) Praxis der Umformtechnik: Umform- und Zerteilverfahren, Werkzeuge, Maschinen, 12th edn. Springer Fachmedien Wiesbaden $\mathrm{GmbH}$, Wiesbaden

14. Friedrich HE (ed) (2017) Leichtbau in der Fahrzeugtechnik, 2. Aufl. 2017. SpringerLink Bücher. Springer Fachmedien Wiesbaden, Wiesbaden

15. EC-European Commission (2019) Regulation (EU) 2019/631 of the European parliament and of the council of 17 April 2019 setting $\mathrm{CO}_{2}$ emission performance standards for new passenger cars and for new light commercial vehicles, and repealing Regulations (EC) No 443/2009 and (EU) No 510/2011 (recast). Off J Eur Union L111:13-53

16. Eshtayeh MM, Hrairi M, Mohiuddin AKM (2016) Clinching process for joining dissimilar materials: state of the art. Int J Adv Manuf Technol 82:179-195. https://doi.org/10.1007/ s00170-015-7363-0

17. Weiß D, Schramm B, Kullmer G (2020) Development of a special specimen geometry for the experimental determination of fracture mechanical parameters of clinchable metal sheets. Procedia Struct Integr 28:2335-2341. https://doi.org/10.1016/j.prostr.2020.11.081

18. Weiß D, Schramm B, Kullmer G (2021) Numerical and experimental fracture mechanical investigations of clinchable sheet metals made of HCT590X. Key Eng Mater 883:127-132. https://doi. org/10.4028/www.scientific.net/KEM.883.127
19. Bauer B, Reschetnik W, Kullmer G, Richard HA (2018) Cracksize measurement of additive manufactured plastics based on the DCPD method. Mater Perform Charact 7:217-223. https://doi. org/10.1520/MPC20170148

20. Bär J (2020) Crack detection and crack length measurement with the DC potential drop method-possibilities, challenges and new developments. Appl Sci 10:8559. https://doi.org/10.3390/app10 238559

21. Riemer A (2015) Einfluss von Werkstoff, Prozessführung und Wärmebehandlung auf das bruchmechanische Verhalten von Laserstrahlschmelzbauteilen. Dissertation, Paderborn University

22. Sander M, Richard HA, Kullmer G (2002) FAM Control-Ein Mess- und Steuerungssystem zur automatischen Durchführung von Rissausbreitungsversuchen bei beliebiger Belastung. In: Frenz $\mathrm{H}$, Wehrstedt A (eds) Kennwertermittlung für die Praxis. WileyVCH Verlag GmbH \& Co. KGaA, Weinheim, pp 160-166

23. Gross D, Seelig T (2018) Fracture mechanics. Springer International Publishing, Cham

24. Branco R, Antunes FV, Costa JD (2015) A review on 3D-FE adaptive remeshing techniques for crack growth modelling. Eng Fract Mech 141:170-195. https://doi.org/10.1016/j.engfracmech.2015. 05.023

25. Rabold F, Kuna M, Leibelt T (2013) Procrack: a software for simulating three-dimensional fatigue crack growth. In: Apel T, Steinbach O (eds) Advanced finite element methods and applications, vol 66. Springer, Berlin, pp 355-374

26. Romlay F, Ouyang H, Ariffin AK, Mohamed NAN (2010) Modeling of fatigue crack propagation using dual boundary element method and Gaussian Monte Carlo method. Eng Anal Bound Elem 34:297-305. https://doi.org/10.1016/j.enganabound.2009. 09.006

27. Peng X, Atroshchenko E, Kerfriden P, Bordas SPA (2017) Isogeometric boundary element methods for three dimensional static fracture and fatigue crack growth. Comput Methods Appl Mech Eng 316:151-185. https://doi.org/10.1016/j.cma.2016.05.038

28. Kuna M (2013) Finite elements in fracture mechanics: theory, numeric, applications. Solid mechanics and its applications, vol 201. Springer, Dordrecht

29. Fulland M, Schöllmann M, Richard HA (2000) ADAPCRACK3D-development of the program for simulation of threedimensional crack propagation processes. Adv Comput Eng Sci 1:948-953

30. Joy TD, Brüggemann J-P, Kullmer G (2018) Crack growth simulation with Adapcrack3D in 3D structures under the influence of temperature. Procedia Struct Integr 13:328-333. https://doi.org/ 10.1016/j.prostr.2018.12.055

31. Carter BJ, Wawrzynek PA, Ingraffea AR (2000) Automated 3-D crack growth simulation. Int J Numer Methods Eng 47:229-253. https://doi.org/10.1002/(SICI)1097-0207(20000110/30)47:1/3\% 3c229:AID-NME769\%3e3.0.CO;2-2

32. Sheldon $\mathbf{J}$ (1999) Investigation of the effects of shed-rate, initial $\mathrm{Kmax}$, and geometric constraint on $\Delta \mathrm{Kth}$ in Ti-6Al-4V at room temperature. Int J Fatigue 21:733-741. https://doi.org/10.1016/ S0142-1123(99)00037-7

33. Clark T (1997) The influence of the K gradient and Kcmax level on fatigue response during the Kcmax threshold testing of Van 80 steel and Astroloy. Int J Fatigue 19:177-182. https://doi.org/10. 1016/S0142-1123(96)00026-6

34. Sander M (2018) Sicherheit und Betriebsfestigkeit Von Maschinen und Anlagen: Konzepte und Methoden Zur Lebensdauervorhersage, 2nd edn. Springer, Berlin

35. Perez N (2017) Fracture mechanics. Springer eBook collection engineering, 2nd edn. Springer International Publishing, Cham

Publisher's Note Springer Nature remains neutral with regard to jurisdictional claims in published maps and institutional affiliations. 